\title{
Advanced materials and processes enabling sustainable growth in the aeronautic industry
}

\author{
H. Lohner ${ }^{1}$, I. Delay-Saunders ${ }^{2}$, S. van der Veen ${ }^{3}$ \& A. Martinet ${ }^{3}$ \\ ${ }^{1}$ Airbus Operations GmbH, Bremen, Germany \\ ${ }^{2}$ Airbus Operations Ltd, Filton, UK \\ ${ }^{3}$ Airbus Operations SAS, Toulouse, France
}

\begin{abstract}
Due to the importance of fulfilling the actual and upcoming environmental legislation and the major goal of the European Aeronautic Defence and Space Company (EADS) "Vision 2020" strategic roadmap; which aims at maximising the benefits of products and services while minimising the environmental impact, it is an Airbus main objective to develop eco-efficient materials. These advanced materials in combination with the corresponding processes are an enabler for a sustainable growth in the aeronautic industry. Under consideration of the economical effects, these processes will be implemented into the production line.

This paper presents the Airbus environmental objectives for the coming years and examines how Airbus steers research and development to implement aircraft environmentally friendly solutions. Examples of eco-efficient material development and of ideas for aircraft dismantling at the end of its life will be presented.

Keywords: materials and processes, life cycle assessment, aircraft end of life, reuse, recycling, recovering, environmental criteria in TRL, research.
\end{abstract}

\section{Introduction}

The aeronautic industry as well as the worldwide air traffic showed a constant growth for the past decades. Vossen et al. [1] summarized that the world's airlines transported more than 2.2 billion passengers in 2008 and transported approximately $40 \%$ of world trade (measured by value). Approximately 2000 airlines worldwide have a total fleet of nearly 23000 aircraft and serve about 3750 airports through a route network of several million miles managed by 
around 160 air navigation service providers. According to Berster et al. [2] the global air traffic has grown substantially in the past. The pace of growth was only slowed by oil and financial crises, terrorism and wars (see figure 1). The number of passengers transported worldwide in air transportation has reached a volume of almost 2.500 million in 2010, since 1994 this volume has almost doubled with an average annual growth rate of $4.3 \%$. The strong growth since 2003 has been influenced mainly by the upcoming of low cost carriers in the US and Europe.

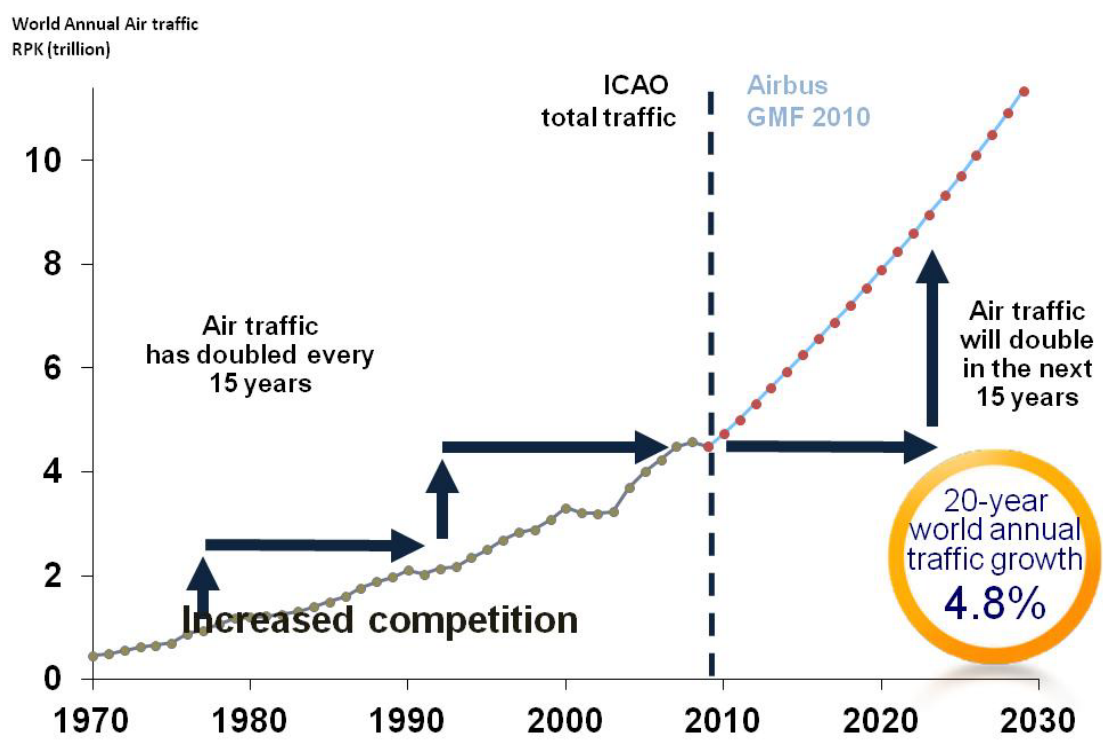

Figure 1: Development of global air traffic [3].

It can be concluded that air traffic doubles each 12 to 15 years and also the assumptions for the future grow given by aircraft producers or by the Advisory Council for Aeronautics Research in Europe (ACARE) are in the same range as shown in figure 1 .

In previous years progress has been made to reduce the environmental impact of the aeronautic industry. In figure 2 the relative fuel consumption per seat is shown over the years. Due to the introduction of engines with better efficiency and the use of low weight materials respectively structures the fuel burn per seat could be reduced by up to $70 \%$. Also recently in other aspects as noise reduction or replacement of hazardous materials good progress has been made.

Additional actions need to be initiated, if the predicted growth of aeronautic sector shall not have negative influence on environment. Aviation produces around $2 \%$ of the world's manmade emissions of carbon dioxide $\left(\mathrm{CO}_{2}\right)$, according to the United Nations Intergovernmental Panel on Climate Change (IPCC). To meet increasing demand the IPCC forecasts show that the increase will be around $3 \%$ in 2050 . 


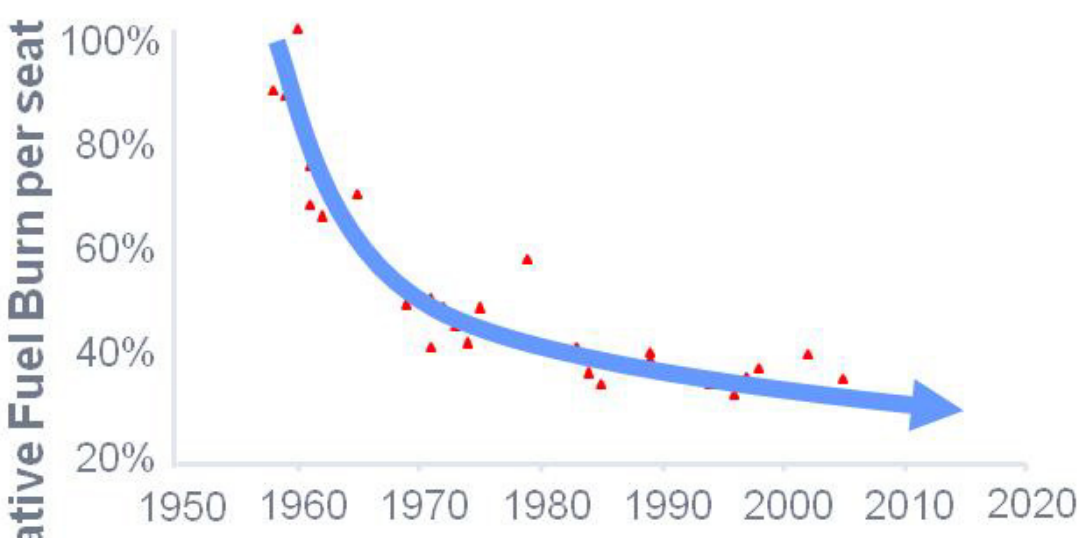

Figure 2: Development of fuel burn per seat.

However, a growing carbon footprint is unacceptable for any industry; therefore the international effort to reduce the emission of green house gases is initiated by the aeronautical industry. Also other impacts on the environment are evident; emission of nitrogen oxides NOx, energy consumption or noise emission are challenges to be overcome.

To limit the environmental influence resulting from air traffic growth ACARE gave guidelines for aeronautic related research and development in the European Union in Vision 2020 [4] and Flight path 2050 [5]. The main aspects of these documents for the development of materials and processes to be used for aircraft application will be shown in section 2 .

Also in the US recommendations are given in the "next generation air transportation systems plan" to solve the challenges related with future increased air traffic as stated by Maurice and Burleson [6]. These recommendations contain five main aspects to reach environmental targets is proposed:

- Advanced scientific understanding

- Advance and accelerate maturation of clean, quiet and energy efficient aircraft technologies

- Develop and implement clean, quiet and energy efficient operational procedures

- Develop alternative fuels

- Use policy, environmental standards and marked based options

To evaluate and also to quantify the effect of the aeronautic industry on the environment the whole life cycle needs to be considered. Life cycle starts from the raw material used for aircraft production followed by the manufacturing and assembly of the aircraft continued by aircraft operation by the airlines and ends 
with aircraft end of life. For each phase of the life cycle the environmental target will differ as well as the focus of the necessary research and development work.

A sustainable growth in aeronautic industry to reduce environmental impact has to be ensured. New/alternative engines combined with alternative fuels and enhanced airframe technologies will play a key role in achieving aviation environmental and energy targets [6]. Additional research and development effort is needed to provide advanced solutions for materials and related processes. These solutions are prerequisite to enable green aircraft technology.

\section{Environmental targets}

As already shown the development of eco-efficient materials and corresponding industrial process is key to reduce the environmental impact of the aeronautic industry [7]. Fulfil legislative requirements as e.g. REACH or solvent legislation is obviously the minimum requirement for aeronautic industry development work on the way to design a green aircraft. In addition various company internal commitments given e.g. in the frame of ISO 14001 certification has to be considered. In this article the following main three phases from aircraft life cycle will be discussed:

\subsection{Industrial}

Each manufacturing activity has been assessed to determine their environmental aspects and to identify those which have or can have any significant impacts on the Environment taking into account the quantity, the consequence, the local sensitivity. The outcomes of these studies show that during the industrial phase Airbus has to focus on the following areas:

1. Waste

2. Use of raw materials

3. Energy use

4. Water discharge

5. Air emissions (Volatile Organic Compounds, $\mathrm{CO}_{2}, \mathrm{SO}_{\mathrm{x}}, \mathrm{NO}_{\mathrm{x}} \ldots$ ).

In line with the ACARE vision 2020 [4] and as already presented [8] it is targeted to reduce the generated waste and the Air emissions (here $\mathrm{CO}_{2}$ and VoC) by $50 \%$ until 2020. The reference for the reduction is the year 2006 assuming iso-perimeter and iso-production. The use of energy in production is planned to be reduced by $30 \%$ and the industrial water discharge is targeted to be reduced by $80 \%$.

Airbus is concerned about preserving non-renewable resources such as fossil fuels and to protect potentially renewable resources, like water by recycling it for certain industrial processes such as surface treatment, reducing its evaporation by lowering the baths' temperature and minimising rinse levels as far as possible. 


\subsection{Aviation}

In the ACARE flight path 2050, [5] several long term targets give a guide for future research work. A first target is a $\mathrm{CO}_{2}$ neutral growth, followed by a $75 \%$ $\mathrm{CO}_{2}$ reduction of $\mathrm{CO}_{2}$ emission per passenger and $\mathrm{km}$ compared to the year 2000. The $\mathrm{NO}_{\mathrm{x}}$ emission is planned to be reduce in the same way by $90 \%$. Other assumptions and proposals in Flight path 2050 are the use of more materials from renewable sources as well as complete recyclable air vehicles.

Structural weight reductions from using composites result in less fuel burn during the operational life of the aircraft. Composites are corrosion free, whilst reducing the quantity of chemicals used to protect the structural components. So overall, they are a significant factor in the reduction of the air transport environmental impact.

Even though Jet Fuel (kerosene) is a good fuel for aviation (reliable product, low freezing point, good energy content...) it remains a non-renewable fossil energy. The demand for such resources is increasing worldwide, while facing at the same time, requirements and expectation to reduce environmental impacts (climate change, air quality...).

With the first generation of bio fuel, feedstock was competing with land and water use for food crops or carbon sinks such as rain forest. For the next generation, the aviation industry is committed to use only biofuels that are grown in a sustainable way [9].

\subsection{Aircraft end of life}

Considering the fact that by 2028, around 7,000 aircraft will no longer be flying, aircraft producers are concerned about the need for decommissioning, dismantling and recycling those aircraft in an environmentally responsible manner.

In order to achieve such an ambition, Airbus, together with public and private partners, have set up an experimental centre at Tarbes Airport (South West of France) where related procedures are being trailed out. Airbus' proposed approach relies in the experience of the EU funded project PAMELA (Process for Advanced Management of End of Life of Aircraft) as e.g. reported by Feldhusen et al. [10]. The experimental project ended in 2007 and demonstrates that for conventional aircraft design (metallic fuselage and wings) up to 85 percent of aircraft's components can be easily recycled, reused or recovered. The end of life feedback experience from the PAMELA project has been integrated into one guideline; recommending best practices that could be implemented into the design phase to optimise aircraft recyclability so as to support the specialists in the choice of materials by integrating recycling principles. Such guideline constitutes a basis for integrating recyclability criteria in design rule guidance or materials and processes selections. The PAMELA project is now pursued by a second more industrial phase called TARMAC-AEROSAVE. Such an integrated approach throughout the full life cycle up to the end-of-life is the right way to better understand and control aircraft environmental impacts. 
Other initiatives have been launched with specialised partners to improve the recycling of Carbon Fiber Reinforced Plastics (CFRP) and in particular optimise the use of recovered fibres in aerospace and other industrial applications. Even if much research into CFRP recycling has been completed and also processes for material recycling (especially for uncured pre-preg material) are available and in use as e.g. presented by Pickering et al. [11], still no recycling process is available that results in a long fibre recyclate that can be use for high technology applications. However Airbus is acting as a catalyst on recycling activities, testing internally solvolysis technology, determining the environmental footprint of recycling treatments and looking for recyclable reusable ancillary materials. On top of recycling activities, Airbus is continuously minimising waste production. Other activities are forecasted to find polymers coming from renewable sources that could also facilitate recycling operations.

\section{How to steer research and development to green solutions}

Even if some visionary aims shown in the section before are planned for the far future, the related research work has to be initiated now to get a chance to meet the challenging targets. On the other hand additional effort is needed to fulfil the more concrete short term targets of ACARE Vision 2020.

When a research project is launched its progress is measured regularly by an Airbus internal technical readiness level (TRL) review process. This review process is based on the original process proposed by NASA [12], but refined to Airbus specific research and development needs.

Environmental criteria are introduced at low TRL levels to assess the environmental performances of a product/technology over its life cycle. The objective is to intervene at the earliest stage of the technology development to have a better understanding and visibility of potential environmental impacts, whether positive or negative, and steer further development steps towards the most eco-efficient solution.

There are five life cycle phases:

- Raw Materials: extraction and production of primary materials involved

- Transport: distance from the processing of the raw material to the final product's distribution

- Manufacturing: industrial processes and assemblies implemented during the manufacturing

- Operation: use and maintenance steps during the in-service phase

- End of life: dismantlement and different scenario for the end of life of parts/assemblies

These environmental criteria are adapted at each gate review depending on the maturity level of the assessed technology. At the first step, criteria permit to sort out technologies having an Environmental footprint. In a second step, 
starting with development phase, a qualitative assessment of the following environmental aspects is performed:

- Energy consumption

- $\quad$ Air emissions (eg.: $\mathrm{CO}_{2}$ and other greenhouse gases solvents/VOC...)

- Materials: consumption, toxicity, sustainability, recyclability

- Waste production and treatment

In a next step a complete life cycle for a process or material under development can be requested if relevant to evaluate and quantify the environmental impact of the technology in detail [7]. The results can then be used to give a simple and efficient feedback to specialists and designers on the environmental footprint of different technological options and steer design choices. In short, Life cycle assessment is a key tool for technology development as it can:

- Provide complete and objective view of environmental benefits of technologies

- Bring the knowledge to reduce high impact areas and anticipate regulatory constraints or new requirements during development

- Steer research and development towards green technologies

\section{Examples for the development of environmental friendly or compliant materials and processes}

During the last years various materials and processes developments have been launched to reduce aircraft environmental footprint from its production to its end of life. Some have been already introduced, especially low weight materials contributing to the limited increase of fuel consumption in air traffic. In this section some examples of environmental friendly developments will be shown.

\subsection{Aircraft production}

\section{Cleaner for aircraft cleaning with low volatile organic compounds (VOC)}

In the past the cleaning agents, which were used before the final paint application, were containing 100\% VOC. In 2010 the first test aircraft was cleaned with a low-VOC cleaning agent. One of the major challenges of the lowVOC cleaning is the very long evaporation time compared to the VOC cleaning. So several of the exiting standard test methods have to be changed and fitted to the new cleaners. The low-VOC cleaning agent was qualified and the cleaner is introduced to the final paint shop for A320 aircrafts in Hamburg. By the new low-VOC cleaning agent the overall VOC consumption of the A320 final paint shop could be reduced by more than $30 \%$. VOC emissions caused only by cleaning solvents could be reduced by $90 \%$ [7]. 


\section{Chromate replacement and $\mathrm{REACH}$}

The development and the introduction of chromate free materials and processes into aircraft manufacturing has been under progress for many years. While the development work for some technologies e.g. a chromate free corrosion inhibiting primer is still ongoing, could others have been introduced into the production. As an example Renner describes the introduction of chromate free anodizing processes for aluminium pre treatment [13, 14]. The aluminium alloy is treated by electro galvanic process to generate an anodizing layer that provides increased corrosion performance and enables good adhesion for the coating. Today the tartaric sulphuric acid anodizing process is standard and has replaced the chromate acid anodizing process. For a specific bonding pre-treatment the phosphoric sulphuric acid anodizing have been implemented into production. In addition to the ban of the carcinogen and REACH relevant chromate from the process, these alternative anodizing technologies offer additional advantages in the energy consumption. Both treatment time, as well as the necessary voltage, of the anodizing processes are reduced by round about $50 \%$.

Other production steps in the metal treatment process are still a subject of investigation as the introduction of borate free cleaning processes at the beginning of the treatment process chain, or the final chromate free sealing of the anodizing film.

\subsection{Aircraft operation}

\section{Continuous improvement - New engine option}

In the past two aspects have contributed to the reduction of aircraft fuel burn. In addition to the introduction of engines with higher efficiency [6] the use of advanced low weight materials, combined with efficient design solutions have enabled a constant growth of air traffic with only limited increase of emissions. An actual example of this way to improve aircraft efficiency is the A320neo (new engine option). It provides minimum change with maximum benefit through the incorporation of two new engine choices along with large wing tip devices, so called Sharklets. These improvements will result in fuel savings of $15 \%$ compared to the today's single aisle configuration and an additional flight distance of 500 nautical miles (950 kilometres), or the ability to carry two tonnes more payload at a given range. The environmental consequence is an emission of approximately 3,600 tonnes less $\mathrm{CO}_{2}$ per aircraft per year combined with a reduction in $\mathrm{NO}_{\mathrm{x}}$ emissions and also reduced engine noise.

The development of the A320neo underlines the fact that improvement in the environmental impact of a product can go hand in hand with economical benefit. Since Airbus' launched the A320neo in December 2010, some 1,420 orders and commitments have been logged for this enhanced family as of November 2011 setting a sales record of its own with bookings from airlines and leasing companies alike. 


\section{Disruptive innovation - Low drag aircraft}

Another important aspect for the reduction of the fuel burn of an aircraft is its aerodynamic design. By realising a laminar flow at the wings, the drag of the aircraft can be reduced significantly compared to a turbulent flow e.g. $[15,16]$. Hansen pointed out that Laminar flow technology is a very promising element for reducing fuel burn. For application of this technology a structural concept has to be developed which can provide high surface quality over the whole life time of the aircraft. A structure concept has to consider production aspects as well as issues during airline operation. Increasing fuel costs will be a major driver to accelerate the application and to increase airline interest [17]. The prerequisite of laminar flow concept is the development of materials and processes that are able to fulfil the challenging aerodynamic requirements on surface quality under industrial production conditions. It starts with the nearly wave-free surface and a step-less assembly of the structure, the surface preparation and the quality assurance and ends with a contamination free surface under in-flight condition. Especially material long term performance and its erosion resistance are key properties to allow natural laminar flow condition during aircraft operation. Contamination on the surfaces e.g. resulted by insects (see figure 3 ) or the roughening of the surface by rain or sand erosion effects can influence and disturb the laminar flow. The actual progress in material development to ensure anti contamination resp. easy to clean surfaces is summarised by Grünke [18].

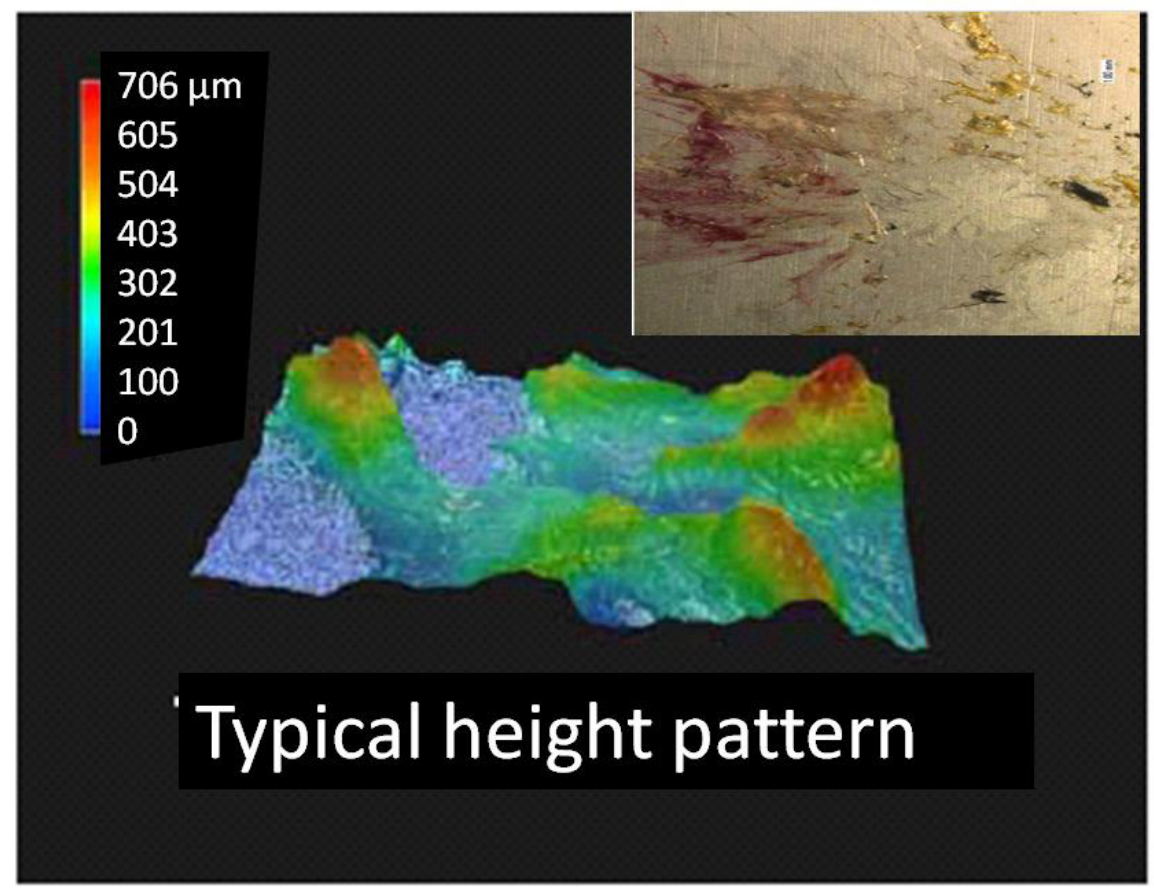

Figure 3: Insect contamination and example of typical height pattern. 
Close cooperation between the main disciplines aerodynamic, structure and manufacturing is mandatory to find a solution which is the best compromise at aircraft level.

To reduce the aircraft drag in areas with turbulent flow condition, a special structured surface, called riblets are currently under investigation. The aerodynamic efficiency of such structures have been shown in various experimental investigations as summarized e.g. by Bechert et al. [19] and have been demonstrated also under in-service conditions. Also for this technology material behaviour and the related application and removal processes play the key role to introduce this technology to the market and to take benefit for the environment. Especially the long term stability of the structured foils investigated in the past was not sufficient. Also aspects for an industrial application and removal process under in service condition were not fully clarified. Stenzel et al. [20] and Gradert [21] give the status of actual development progress to prove maturity of a structured coating and the related processes.

\subsection{Aircraft end of life}

In the frame of ECO Design for Airframe Structures ITD Airbus and its partners are involved in various research activities to prepare future aircraft's end of life. Aspects as identification and mapping of materials, recycling of metal and CFRP materials, (both thermosets and thermoplastics) as well as material recycling of insulation materials are under investigation.

The main involvement of Airbus is the identification and mapping of aircraft materials at end of life. The investigated and selected tools for material identification should make sorting of material simpler on a/c dismantling. By simplifying and accelerating this process of analysis, the recycling industry could gain access to secondary raw materials sorted into types with near-perfect precision, which would enable the manufacture of high-grade products from recycled materials. Three methods appear as a good solution for the identification of materials, more precisely polymers and composites.

Methods selected for further investigation are handheld devices hereinafter:

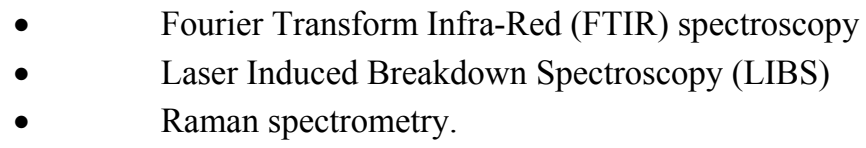

\section{Conclusion}

Environmental criteria and requirements are leading the development of new materials and associated processes for aircraft application.

Apart from the need to be compliant with actual and upcoming environmental legislation, solutions for a reduced effect of the aeronautic industry on the environment are needed to meet the challenges related to the predicted growth of air traffic. Advanced materials and processes enable these solutions for aircraft 
production as well as for aircraft operation. Future developments will be aligned with the objectives of the strategic research and innovation agenda of flight path 2050

- Meeting societal and market needs

- Maintaining and extending industrial leadership

- Protecting the environment and the energy supply

- Ensuring safety and security

- Prioritising research, testing capabilities and education [5]

\section{Acknowledgements}

The authors thank the European Commission to support parts of this work in the frame of the Joint Technology Initiative Clean Sky. The work was realized as part of the ECO Design for Airframe Structures ITD.

\section{References}

[1] Vossen T. W. M., Hoffman R., Mukherjee A., Quantitative Problem Solving Methods in the Airline Industry. International Series in Operations Research \& Management Science Volume 169. Air Traffic Flow Management. Springer Verlag London, p. 385-453, 2012.

[2] Berster P., Gelhausen M., Wilken D., Do airport capacity constraints have a serious impact on the future development of global air traffic? Proc. of 2011 World Conference of Air Transport Research Society (ATRS): Sydney, p. 1-22, 2011.

[3] Williams G., The European R \& T Vision for Aeronautics in 2050, SAE Aerotech conference, Toulouse 2011.

[4] European Aeronautics: A vision for 2020, Office for official publications of the European Communities, Luxembourg 2001, ISBN 92-994-0559-7.

[5] European Aeronautics: Flightpath 2050 Europe's Vision for Aviation, Publications Office of the European Union, Luxembourg 2011, ISBN 97892-79-19724-6.

[6] Maurice L., Burleson C., Transport, \& the Environment: Addressing the sustainable mobility paradigm. (Chapter 4) Aviation policy and governance, Ed. O. Inderwildy, D King. Springer Verlag London, p.387400, 2012.

[7] Lohner H., Martinet A., Beneke M., Langer B., Kalyan P., Hesse K., DelaySaunders I.: Eco-efficient materials for bluer sky. Aerospace Engineering 16 (2011)11, p.8-17.

[8] Lohner, H., Kröger-Kallies, B., Rives, B., Fangmeier, A., Aircraft surface protection - Principales, application, future trends. Deutscher Luft und Raumfahrt Kongress, Bremen, 2011.

[9] ATAG www.enviro.aero May 2009. 
[10] Feldhusen J., Pollmanns J., Heller J. E., Glocalized Solutions for Sustainability in Manufacturing, Proc. 18th CIRP International Conference on Life Cycle Engineering, End of life strategies in the aviation industry, Ed. Hesselbach J., Herrmann C., Springer Verlag Heidelberg, p 459-464, 2011.

[11] Pickering S. J., Wong K., Turner T., Warrior N. A., Reducing Environmental Impact of Carbon Fibre Composites through Recycling, $S A E$ Aerotech conference, Toulouse, 2011.

[12] Mankins J.C., technical readiness level, 1995.

[13] Renner M., Green surface technologies, 17th international conference on surface treatments in the aeronautic and aerospace industries SurfAir, Biarritz, p.251-258, 2008.

[14] Renner M.: Implementation of a new galvanic process. International networking forum on aircraft and aerospace coating. München 2009.

[15] Redeker G., Horstmann K. H., Koester H., Thiede P., Szodruch J., Design of Natural Laminar Flow Glove on a Transport Aircraft, AIAA Paper 903043-CP, Aug. 1990.

[16] Schrauf G., Large-Scale Laminar-Flow Test Evaluated with Linear Stability Theory, AIAA Journal of Aircraft, 41 (2004) 2, pp. 224- 230.

[17] Hansen H., Overview about laminar flow activities at Airbus. Proc. of Deutscher Luft und Raumfahrt Kongress, Bremen, p. 45-54, 2011.

[18] Grünke S., Anti contamination and easy to clean surfaces for aircraft efficiency, 19th international conference on surface treatments in the aeronautic and aerospace industries SurfAir, Biarritz.

[19] Bechert D.W., Bruse M., Hage, W. Meyer R., Fluid Mechanics of Biological Surfaces and their Technological Application, Naturwissenschaften, 87 (2000) p. 157-171.

[20] Stenzel V., Wilke, Y., Hage, W., Drag-reducing paints for the reduction of fuel consumption in aviation and shipping, Progress in organic coatings 70 (2011) 224-229.

[21] Gradert I., Micro structured coating for skin friction reduction, 19th international conference on surface treatments in the aeronautic and aerospace industries SurfAir, Biarritz. 